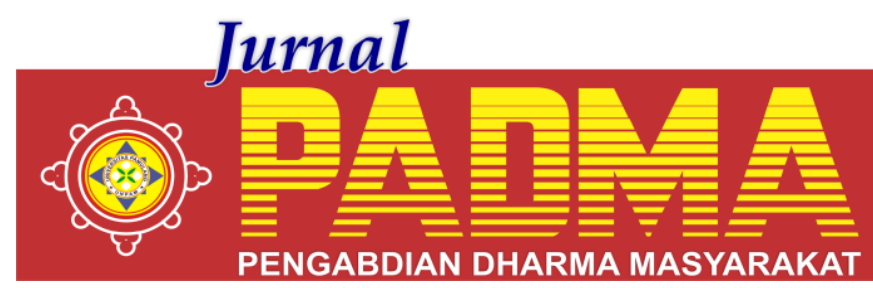

VOLUME I, NOMOR 4, OKTOBER 2021

\title{
PENGGUNAAN ENGLISH VOCABULARY GAMES UNTUK MENINGKATKAN MINAT BELAJAR BAHASA INGGRIS SISWA SEKOLAH DASAR INPRES KAROT SELAMA MASA PANDEMI COVID-19
}

\author{
${ }^{1}$ Kristina Kresna Wanti, ${ }^{2}$ Katarina Ilaning Alur, ${ }^{3}$ Maria Oktaviana, ${ }^{4 *}$ Gabriel Fredi Daar \\ Universitas Katolik Indonesia Santu Paulus Ruteng, Nusa Tenggara Timur, Indonesia \\ 호.kristinewanti@gmail.com, ${ }^{2}$ katarinailanalur@gmail.com, ${ }^{4 *}$ freddydaar@gmail.com
}

\begin{abstract}
Abstrak
Kegiatan pengabdian kepada masyarakat ini bertujuan untuk meningkatkan minat belajar bahasa Inggris Sekolah Dasar. Kegiatan dilakukan di Sekolah dasar Inpres Karot, Kabupaten Manggarai NTT. Kegiatan dilakukan dalam bentuk praktik dan simulasi bermain games kosa kata berbahasa Inggris. Berdasarkan hasil evaluasi melalui obervasi, ditemukan bahwa siswa SDI Karot senang dan antusias mengikuti kegiatan pembelajaran bahasa Inggris dengan menggunakan Vocabulary Games. Ini terlihat pada keaktifan dan partisipasi siswa dalam mengikuti diskusi kelompok dan dalam menjawab setiap pertanyaan yang diajukan pelaksana PKM. Dengan demikian dapat direkomendasikan bahwa penerapan Vocabulary Games hendaknya selalu diimplementasikan dalam kegiatan pembelajaran kepada siswa SD. Konsekuensinya adalah guru mempersiapkan dan merancang media secara sistematis yang dapat menunjang penerapan English Vocabulary Games.
\end{abstract}

Kata Kunci: Bahasa Inggris, Vocabulary Games, Minat, Siswa Sekolah Dasar

\section{Abstract}

This community service activity aims to increase interest in learning English in Elementary School. The activity was carried out at the Karot Inpres Elementary School, Manggarai Regency, NTT. Activities carried out in the form of practice and simulation playing English vocabulary games. Based on the results of the evaluation through observation, it was found that SDI Karot students were happy and enthusiastic about participating in English learning activities using Vocabulary Games. This can be seen in the activeness and participation of students in participating in group discussions and in answering every question posed by PKM implementers. Thus, it can be recommended that the implementation of Vocabulary Games should always be implemented in learning activities for elementary school students. The consequence is that teachers prepare and design media systematically that can support the implementation of English Vocabulary Games.

Keywords: English, Vocabulary Games, Interest, Elementary School Students

\section{PENDAHULUAN}

Ditengah perkembangan dunia yang semakin moderen, ada banyak tuntutan zaman di era globalisasi ini yang harus dipenuhi termasuk didalamnya menyangkut penguasaan bahasa-bahasa asing untuk berkomunikasi dan salah satu bahasa asing tersebut yaitu Bahasa Inggris. Pemerintah Indonesia menyadari bahwa dunia pendidikan harus mengalami perkembangan dalam bidang ilmu pengetahuan dan teknologi dengan tujuan untuk menghilangkan batas antarnegara. Oleh karena itu, tahun 1993 pemerintah membuat suatu kebijakan yakni menetapkan bahasa Inggris diajarkan sejak dini, dan ini bisa dilihat dari Kebijakan Pemerintah melalui
Departemen Pendidikan dan Kebudayaan Republik Indonesia (Depdikbud RI) No. 0487/1992, Bab VIII yang menyatakan bahwa SD dapat menambahkan mata pelajaran dalam kurikulumnya, termasuk didalamnya adalah Bahasa inggris sebagai muatan lokal. Menteri Pendidikan dan Kebudayaan (Mendikbud) Nadiem Makarim pada Mei tahun 2020 meghidupkan kembali mata pelajaran Bahasa Inggris di jejang SD. Beberapa penelitian terkait implementasi bahasa Inggris di SD menunjukan bahwa kepala sekolah, guru dan siswa mendukung implementasi bahasa Inggris tersebut meskipun beberapa sekolah melakukan modifikasi dalam implementasinya. Maili (2018) dalam penelitiannya kepada sepuluh 
sekolah dasar di Jakarta menunjukkan bahwa guru bahasa Inggris dan Kepala sekolah setuju bahasa Inggris diajarkan kepada siswa sekolah dasar. Selain itu, Kaltsum (2016) dalam penelitiannya tentang Bahasa Inggris Dalam Kurikulum 2013 di Sekolah Dasar menemukan bahwa sekolah Dasar Muhadiyah menerapkan bahasa Inggris untuk hampir semua mata pelajaran namun ada modifikasi untuk mata pelajaran Bahasa Inggris.

Anak usia sekolah menurut WHO yakni anak yang berusia antara 7-15 tahun. Di Indonesia anak usia sekolah itu berkisar antara usia 7-12 tahun. Anak usia ini adalah anak yang mengalami pertumbuhan mental yang sangat pesat, memiliki rasa keingintahuan yang tinggi, mereka senang bermain, senang bergerak atau melakukan dan merasakan sesuatu secara langsung serta bekerja dalam kelompok. Pada usia ini, anak juga mengalami perkembangan kognitif untuk menerima, mengolah, sampai memahami informasi yang diterima.

Sekolah Dasar Inpres (SDI) Karot merupakan salah satu sekolah di Kota Ruteng. Sekolah ini sudah menyediakan mata pelajaran Bahasa Inggris sebagai mata pelajaran muatan lokal. Dengan adanya mata pelajaran ini, guru bahasa Inggris dipersiapkan agar implementasi pembelajaran di sekolah sejalan dengan tuntutan kebutuhan terutama terkait keterampilan yang menunjang masa depan siswa.

Untuk meningkatkan minat belajar Bahasa Inggris pada anak sekolah dasar di SDI Karot, diperlukan lingkungan belajar yang menyenangkan yang dirancang secara sistematis oleh guru bahasa Inggris. Ini berkaitan dengan kemampuan guru atau pengajar untuk menganalisis dan memilih media pembelajaran, metode pembelajaran dan juga strategi pembelajaran yang tepat bagi anak dalam kegiatan pembelajaran Bahasa inggris.

Salah satu strategi dan media yang dapat digunakan guru untuk menghadirkan susana belajar yang menyenangkan dalam kegiatan pembelajaran bahasa Inggris pada siswa sekolah dasar adalah penggunaan Vocabulary Games. Penggunaan vocabulary games dianggap efektik dalam meningkatkan minat dan motivasi belajar bahasa Inggris siswa. Hasil penelitian Amalia (2018) merekomendasikan kepada guru bahasa Inggris untuk mengaplikasikan Vocabulary Self-collection Strategy dalam kegiatan pembelajaran bahasa Inggris. Strategi ini dapat diaplikasikan melalui permainan Vocabulary Games yang dapat meningkatkan penguasaan kosa kata bahasa Inggris yang pada tahap selanjutnya berdampak pada peningkatan kemampuan berbicara bahasa Inggris siswa. Ini telah dibuktikan oleh hasil penelitian Puntadewi dan Enguliana (2018) yang menemukan adanya pengaruh penguasaan kosa kata terhadap kemampuan berbicara bahasa Inggris.

Mengacu beberapa hasil penelitian di atas, pelaksana kegiatan Pengabdian kepada masyarakat mengadakan kegiatan PKM kepada anak usia sekolah dasar khususnya siswa SDI Karot Kabupaten Manggarai NTT melalui penggunaan Vocabulary Games dalam kegiatan pembelajaran Bahasa inggris. Diharapkan kegiatan ini dapat meningkatkan minat belajar Bahasa inggris siswa.

\section{METODE}

1. Solusi Permasalahan

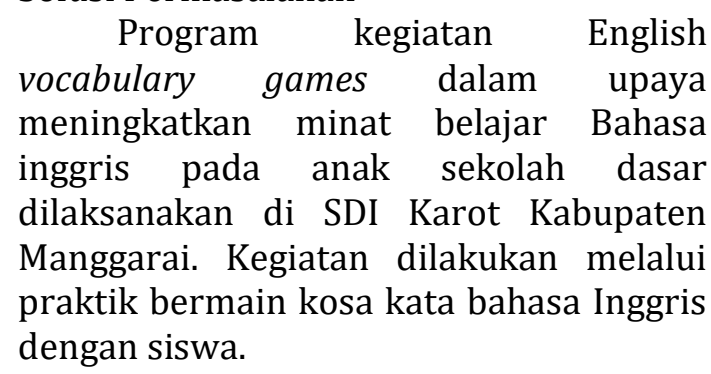

2. Metode Pelaksanaan

Metode yang digunakan dalam pelaksanaan kegiatan ini adalah praktik bermain baik secara individu maupun kelompok dengan bantuan alat peraga dan media yang sudah dirancang dan disiapkan pelaksana PKM.

3. Tahapan Kegiatan

Tahapan kegiatan yang akan dilaksanakan, adalah sebagai berikut;

a. Menetapkan daerah/ lokasi sasaran program PKM

b. Pelaksana meninjau lokasi tempat diadakan program kemitraan untuk studi awal.

c. Penyusunan materi kegiatan PKM

d. Penyusunan jadwal kegiatan PKM.

e. Pelaksana mengajukan izin pelaksanaan kegiatan penyuluhan dan 
pelatihan kepada kepala sekolah SDI Karot.

f. Sosialisasi kegiatan penyuluhan dan pelatihan kepada para guru dan anakanak.

g. Menyelenggarakan kegiatan PKM.

4. Evaluasi Pelaksana Kegiatan

Evaluasi kegiatan permainan kosakata diadakan setelah anak-anak paham dengan pembelajaran yang di ajarkan. Penilaian pada setiap anak didasarkan pada keaktifan saat pembelajaran berlangsung dan review pembelajaran diminggu sebelumnya. Pada minggu ke-8 diharapkan anak-anak sudah menunjukkan minat yang baik untuk belajar Bahasa inggris dengan menguasai banyak kosa kata Bahasa inggris.

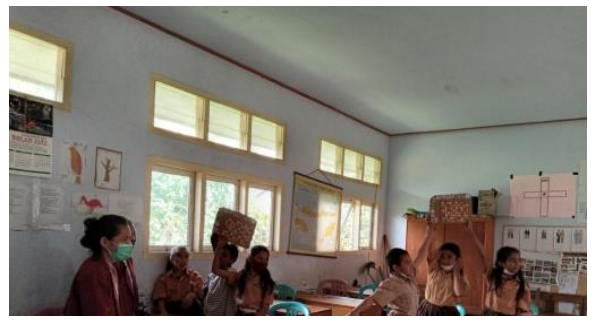

Gambar 1. Siswa menunjukkan hasil diskusi

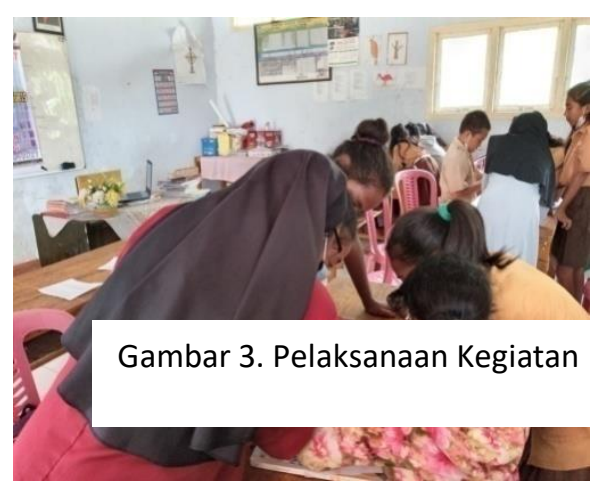

Kegiatan PKM melalui penggunaan English Vocabulary Games merupakan salah satu upaya untuk mengembangkan kemampuan peserta didik atau anak Sekolah Dasar dalam kegiatan pembelajaran bahasa

\section{HASIL DAN PEMBAHASAN}

Kegiatan PKM English vocabulary games diberikan kepada siswa SDI Karot kelas 4-6. Kegiatan ini merupakan bagian dari upaya pelaksana PKM mendorong siswa sejak Sekolah Dasar mengenal dan memahami kosakata Bahasa Inggris sebagai salah satu mata pelajaran wajib pada jenjang SMP, SMA dan Perguruan Tinggi sebagai. Selama kegiatan PKM berlangsung, Anakanak diperkenalkan dengan benda-benda, abjad, tumbuhan, rumah ibadat, nama buah, binatang dan kata kerja dalam Bahasa dalam Bahasa Indonesia yang kemudian diterjemahkan dalam Bahasa inggris. Kegiatan dilakukan sekali seminggu dengan alokasi waktu 2 jam per pertemuan. Anakanak diberi kesempatan untuk membaca, menulis, menghafal, memainkan dan menjawab. Untuk mempermudah observasi serta meningkatkan partisipasi siswa, pelaksana PKM membagi siswa ke dalam kelompok-kelompok kecil yang didampingi oleh salah satu anggota tim pelaksana.
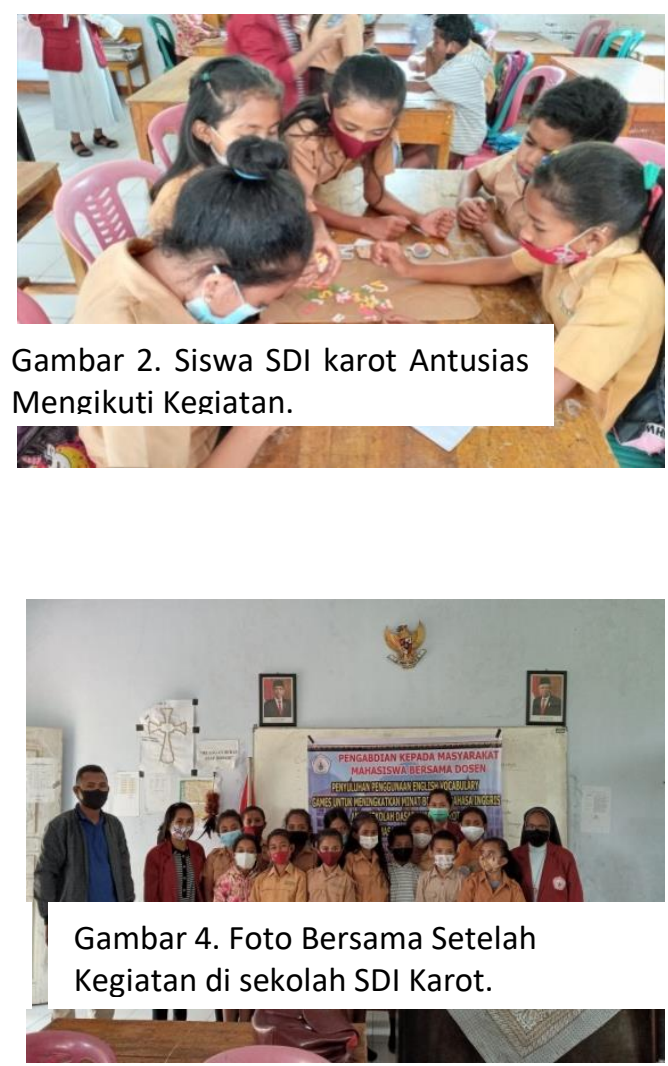

Inggris. Kegiatan ini juga merupakan upaya pelaksana PKM membangkitkan semangat dan minat siswa dalam kegiatan pembelajaran bahasa Inggris. Berdasarkan hasil observasi selama kegiatan berlangsung, 
ditemukan bahwa siswa SDI Karot senang dan antusias mengikuti kegiatan pembelajaran bahasa Inggris dengan menggunakan Vocabulary Games. Ini terlihat pada keaktifan dan partisipasi siswa dalam mengikuti diskusi kelompok dan dalam menjawab setiap pertanyaan yang diajukan pelaksana PKM. Hasil kegiatan PKM ini sejalan dengan beberapa studi dan kegiatan PKM sebelumnya terkait dampak penggunaan Vocabulary Games terhadap Minat belajar bahasa Inggris siswa. Sahrawi, dkk. (2018) dalam kegiatan PKM tentang Pengajaran Kosakata Bahasa Inggris Menggunakan Games Untuk Menarik Minat Belajar Siswa SMP Awaluddin menemukan bahwa kegiatan PKM yang mereka lakukan berpengaruh pada minat siswa dalam pembelajaran bahasa Inggris. Dengan penggunaan Vocabulary Games siswa dapat lebih mudah memahami dan mengingat kosakata selama proses pembelajaran. Selain itu, efektifitas kegiatan belajar mengajar dapat dipantau oleh guru. Siswa juga dapat mengikuti pembelajaran dengan antusias yang tinggi. Materi dapat disampaikan secara menarik oleh pengajar, dan topic dalam materi juga dekat dengan kehidupan seharihari siswa. Selain itu, Trisnadewi dan Lestari (2018) dalam penelitian tentang Pengaruh Language Games Terhadap Kemampuan Berbicaa Bahasa Inggris menujukkan bahwa penerapan language games memiliki pengaruh yang positif dan signifikan terhadap kemampuan berbicara mahasiswa kelas Z STMIK STIKOM Indonesia. Kemampuan berbicara tersebut mencakup pelafalan, kelancaran, dan ketepatan kalimat yang dibuat oleh mahasiswa.

Pelaksaaan kegiatan PKM berjalan dengan lancar meskipun ditemukan sedikit kendala terkait pembagian siswa dalam beberapa shift oleh karena situasi pandemic covid 19. Protokol kesehatan tetap dijaga dengan mencuci tangan, memakai masker, dan menjaga jarak sebelum kegiatan, selama kegiatan dan sesudah kegiatan PKM berlangsung.

Kegiatan PKM Bahasa inggris melalui penggunaan vocabulary games untuk mendapat respon yang positif baik dari kepala sekolah, para guru yang sempat menonton kegiatan dan guru Bahasa inggris. Diharapkan, penerapan English Vocabulary
Games diimplementasikan secara berkelanjutan dalam kegiatan pembelajaran Bahasa Inggris di SDI Karot agar siswa memiliki minat dan kecintaan untuk mempelajari bahasa Inggris sebagai salah satu instrument pengembangan kecakapan hidup di masa depan.

\section{KESIMPULAN}

Kegiatan PKM ini bertujuan untuk menarik dan meningkatkan minat belajar Bahasa Inggris siswa,di SDI Karot Kabupaten Manggarai NTT. Berdasarkan hasil obervasi selama kegiatan, ditemukan bahwa siswa SDI Karot senang dan antusias mengikuti kegiatan pembelajaran bahasa Inggris dengan menggunakan Vocabulary Games. Ini terlihat pada keaktifan dan partisipasi siswa dalam mengikuti diskusi kelompok dan dalam menjawab setiap pertanyaan yang diajukan pelaksana PKM. Dengan demikian dapat direkomendasikan bahwa penerapan Vocabulary Games hendaknya selalu diimplementasikan dalam kegiatan pembelajaran kepada siswa SD. Konsekuensinya adalah guru mempersipakan dan merancang media secara sistematis yang dapat menunjang penerapan English Vocabulary Games.

\section{UCAPAN TERIMA KASIH}

Ucapan terima kasih terutama ditujukan Yayasan Santu Paulus Ruteng yang telah menyediakan dana untuk kelancaran kegiatan PKM ini. Terima kasih juga kepada kepala SDI Karot yang telah memberikan izin dan membantu memperlancar kegiatan PKM ini.

\section{DAFTAR PUSTAKA}

Amalia, Nurlaila Penguasaan Vocabulary Siswa Menggunakan Vocabulary SelfCollection Strategy. Journal of Education Action Research. 2 (2), Pp. 172-179.

Honest Ummi Kaltsum. (2016). Bahasa Inggris Dalam Kurikulum 2013 Di Sekolah Dasar. The 3rd University Research Colloquium 2016

Puntadewi, Enggar Dyah dan Engliana. (2081). The Role of Vocabulary Mastery And Learning Interest In Speaking Proficiency of Indonesian Efl 
Learners. Inference: Journal of English Language Teaching. 1(3).

Sahrawi, Dkk. (2018). Pengajaran Kosakata Bahasa Inggris Menggunakan Games Untuk Menarik Minat Belajar Siswa Smp Awaluddin. Gervasi: Jurnal Pengabdian Kepada Masyarakat 2(2), Pp.166-175

Sjafty Nursiti Mail. (2018). Bahasa Inggris Pada Sekolah Dasar: Mengapa Perlu Dan Mengapa Dipersoalkan. Judika
(Jurnal Pendidikan Unsika). 6(1), Pp.23-28

Trisnadewi, Komang dan Eka Ayu Purnama Lestari. (2018). Pengaruh Language Games Terhadap Kemampuan Berbicaa Bahasa Inggris

Yuangga, K. D., \& Sunarsi, D. (2020). Pengembangan media dan strategi pembelajaran untuk mengatasi permasalahan pembelajaran jarak jauh di pandemi covid-19. JGK (Jurnal Guru Kita), 4(3), 51-58. 